\title{
Keanekaragaman Jamur di Cagar Alam Gunung Mutis Kabupaten Timor Tengah Utara, Nusa Tenggara Timur
}

\author{
Diversity of Mushrooms in Mt. Mutis Nature Reserve, North Central Timor District, East \\ Nusa Tenggara
}

\author{
Hartini Solle $^{1 *}$, Ferdinandus Klau ${ }^{1}$, Simon Taka Nuhamara ${ }^{1}$ \\ ${ }^{1}$ Universitas Kristen Artha Wacana, FKIP, Jl. Adi sucipto, Oesapa \\ Email: hartinisolle21@gmail.com *Penulis untuk korespondensi
}

\begin{abstract}
Mushroom is an organism that play an important role in decomposing complex organic materials into simple materials absorbed by other organisms. The purpose of this research was to know the type of mushrooms and to know the level of diversity of mushroom species in the forest of Mt. Mutis. The method used was the roaming method of each plot, by noting the type of fungus found in the area and followed by the identification of the type of fungus found. Sampling was conducted by collecting and documenting. The results showed that there were 340 individuals in 17 species of fungi with a level of diversity: 1.510 showing a high degree of diversity of fungal species. The most dominant species of mushrooms are Microporus sp and Polyporus sp mushrooms, while other types were still low in existence such as Polyporus squamosus, Coriolus hirsutus, Pycnoporus cinnabarinus, Tyromyces sambuceus, Fomytopsis pinicola, Microporus perula, Trametes orientalis, Piptoporus betulinus, Auricula auricula, Elfvingia applanata, Fomes sp, Laccaria vinaceoavellaneae, Paxillus curtisii, Pleurotus pulmorius.
\end{abstract}

Keyword: Identification, diversity, mushroom, nature preserve, Mutis

\begin{abstract}
Abstrak
Jamur merupakan salah satu organisme yang memegang peranan penting dalam menguraikan bahan organik yang sangat kompleks menjadi bahan sederhana sehingga mudah diserap oleh organisme lainnya. Tujuan penelitian untuk mengetahui jenis jamur dan mengetahui tingkat keanekaragaman jenis jamur pada hutan cagar alam gunung Mutis. Metode yang digunakan adalah metode jelajah setiap plot dengan mencatat jenis jamur yang ditemukan pada kawasan tersebut dan dilanjutkan dengan proses identifikasi jenis jamur yang ditemukan. Pengambilan sampel dengan koleksi dan dokumentasi. Hasil penelitian menunjukkan bahwa terdapat 340 individu pada 17 spesies jamur dengan tingkat keanekaragaman : 1,510 yang menunjukkan tingkat keanekaragam spesies jamur yang tinggi. Spesies jamur yang paling mendominasi adalah jamur Microporus sp dan Polyporus sp, sedangkan jenis lain keberadaannya masih tergolong rendah seperti Polyporus squamosus, Coriolus hirsutus, Pycnoporus cinnabarinus, Tyromyces sambuceus, Fomytopsis pinicola, Microporus perula, Trametes orientalis, Piptoporus betulinus, Auricula polytricha, Auricularia auricula, Elfvingia applanata, Fomes sp, Laccaria vinaceoavellaneae, Paxillus curtisii, Pleurotus pulmorius.
\end{abstract}

Kata kunci: Identifikasi, Keanekaragaman, Jamur, Cagar alam, Mutis

Diterima 20 Juni 2017, disetujui: 3 Juli 2017

\section{Pendahuluan}

Jamur merupakan salah satu organisme yang memegang peranan penting dalam daur kehidupan. Peranan penting dari jamur adalah menguraikan bahan organik yang kompleks yang ada di alam menjadi suatu unsur yang sangat sederhana sehingga mudah diserap dan dimanfaatkan oleh organisme yang lainnya. Jamur merupakan organisme yang bersifat dekomposer, parasitik, dan mutualistik.

Keberadaan jamur di seluruh dunia diperkirakan jumlahnya dapat mencapai 1,5 juta spesies yang diprediksi masih hidup. Akan tetapi 
jumlah jamur teridentifikasi sampai saat ini baru mencapai sekitar 100.000 spesies (Campbell dkk., 2012) yang artinya bahwa masih banyak jumlah spesies jamur yang belum teridentifikasi. Jamur memperoleh makanan atau sumber nutrisi dengan menggunakan suatu alat yang terdiri dari benang-benang halus yang disebut dengan hifa (Anggriawan, 2014). Jamur merupakan organisme eukaryotik, berspora, tidak berklorofil, bereproduksi secara seksual dan aseksual, jamur berdasarkan ukuran tubuhnya ada yang makroskopis yaitu jamur yang berukuran besar, sehingga dapat dilihat dengan mata telanjang dan ada juga jamur yang mikroskopis yaitu jamur yang berukuran kecil dan hanya dapat dilihat dengan menggunakan alat bantu mikroskop (Darwis, 2011).

Menurut Tampubolon (2010), jamur khususnya kelompok jamur makroskopik atau makrofungi (Basidiomycota), merupakan kelompok utama organisme pendegradasi lignoselulosa karena mampu menghasilkan enzim-enzim pendegradasi lignoselulosa seperti selulase, ligninase, dan hemiselulase, sehingga daur materi di alam dapat terus berlangsung.

Identifikasi jamur selain sebagai sumber dan bahan informasi tentang jumlah spesies jamur, juga termasuk dalam salah satu hal terpenting dari delapan poin yang dimasukan dalam deklarasi milenium atau kesepakatan milenium dari seluruh kepala negara anggota PBB yang dilangsungkan di New York, Amerika Serikat tahun 2008 serta dengan lembagalembaga internasional lainnya, deklarasi tersebut dikenal dengan istilah Millenium Development Goals. Salah satu isi dari deklarasi tersebut adalah kelestarian lingkungan dengan mengurangi atau mengantisipasi laju berkurangnya keanekaragaman hayati (Stalker, 2008).

Menurut Proborini (2006), bahwa identifikasi jamur makroskopik berarti identifikasi yang dilakukan dengan cara pengamatan morfologi secara makroskopik. Parameter yang digunakan sebagai acuan untuk mengamati jamur meliputi ciri makroskopik (bentuk, warna dan tekstur tubuh buah, kehadiran cincin dan volva, serta bentuk akrosphora).

Menurut Campbell dkk., (2012), bahwa fungi atau jamur merupakan heterotrof yang dilakukan oleh tumbuhan dan alga. Namun tidak seperti hewan, fungi tidak menelan (memakan) makanannya. Sebagai gantinya, fungi mengabsorbsi nutrien dari lingkungan di luar tubuhnya. Banyak fungi yang melakukan hal ini dengan mensekresikan enzim-enzim hidrolitik kuat ke sekelilingnya. Enzim-enzim ini memecah molekul-molekul kompleks menjadi senyawa-senyawa organik yang lebih kecil sehingga fungi dapat menyerap senyawa itu ke dalam tubuh dan dapat menggunakannya. Beberapa jamur atau fungi bersifat uniseluler, namun sebagian besar bersifat multiseluler, yang mencakup struktur yang kita kenal sebagai cendawan. Diversitas sangat tergantung pada kemerataan individu antarspesies dan bukan hanya pada kekayaan spesiesnya sehingga yang menyebabkan naiknya nilai indeks diversitas adalah kemerataan antarspesies.

\section{Metode Penelitian}

Penelitian ini dilaksanakan di kawasan hutan Cagar Alam Gunung Mutis, Desa Noepesu, Kecamatan Miomaffo Barat, Kabupaten Timor Tengah Utara (TTU), Provinsi NTT.

Metode penelitian yang dilakukan adalah metode purpossive sampling, berdasarkan keberadaan jamur makroskopis yang dianggap mewakili kawasan tersebut, setelah itu dilanjutkan dengan mencatat jumlah individu, koleksi dan dokumentasi.

Penjelajahan dilakukan pada setiap plot, yang arah koleksi dari plot 1 sampai dengan plot 7, dan arah jelajahnya disesuaikan dengan arah transeknya. Jamur yang ditemukan di setiap plot dikoleksi dan diambil setiap jenis untuk diidentifikasi lebih lanjut menggunakan buku kunci determinasi dan buku jamur Jepang (Imazeki dkk., 1988).

\section{Hasil dan Pembahasan}

Secara geografis hutan cagar alam Gunung Mutis (ditunjukkan pada Gambar 1), khususnya lokasi penelitian transek I, terletak di antara $124^{\circ} 14^{\prime}$ 5. 2362" BT dan 09 32' 37. 0176" LS, sedangkan transek II terletak antara $124^{\circ} 14^{\prime} 4$. 6816" BT dan $09^{\circ} 32$ ' 36 2868" LS 
dengan ketinggian $1.167 \mathrm{mdpl}$, kondisi tanah lembab dan tingkat kemiringan yang berbentuk lereng hingga curam serta suhunya berkisar antara $6^{\circ} \mathrm{C}$ sampai dengan $22^{\circ} \mathrm{C}$. Kawasan hutan Mutis telah ditetapkan sebagai kawasan konservasi yang berfungsi sebagai kawasan cagar alam dengan luas sekitar \pm 12.000 ha.

Keanekaragaman adalah kekayaan dan kemerataan. Kekayaan spesies adalah jumlah spesies dari beberapa area dalam beberapa komunitas. Distribusi antara spesies disebut dengan kemerataan spesies atau ekuibilitas spesies. Kemerataan menjadi maksimum bila semua spesies mempunyai jumlah individu sehingga terjadi keanekaragaman spesies atau diversitas spesies. Spora jamur dapat tumbuh dan berkembang menjadi miselium, hingga membentuk tubuh buah yang besar pada kelompok cendawan. Sementara ertumbuhan fungi dipengaruhi oleh faktor substrat, kelembapan, suhu, derajat keasaman substrat $(\mathrm{pH})$.

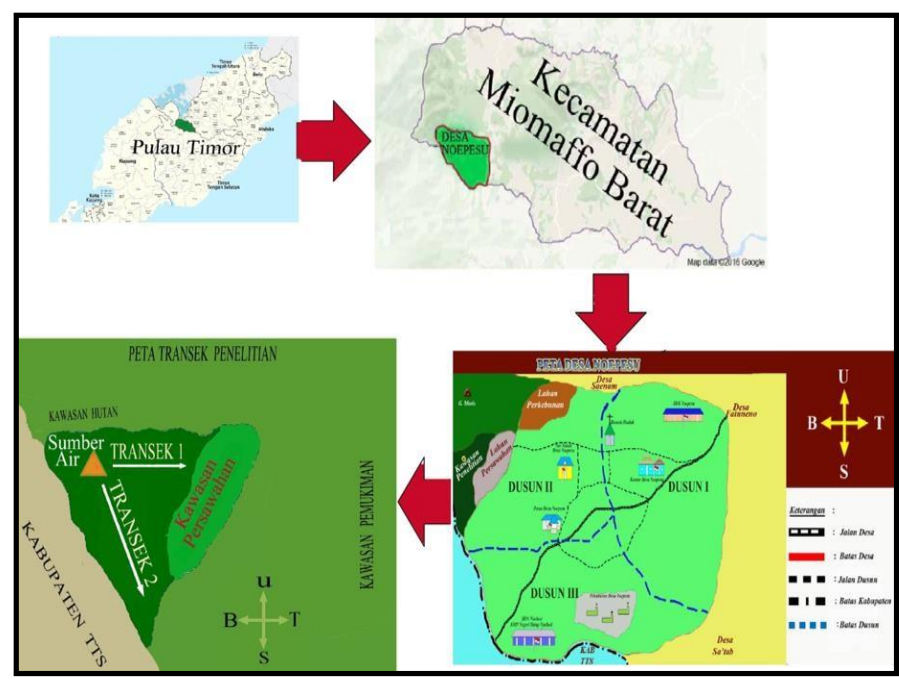

Gambar 1. Peta lokasi penelitian

Tabel 1. Indeks Keanekaragaman Spesies yang ditemukan di Cagar Alam Gunung Mutis

\begin{tabular}{cllcc}
\hline \hline No & Family & \multicolumn{1}{c}{ Nama Spesies } & Jumlah Individu & Indeks diversitas \\
\hline \hline 1 & Polyporaceae & Microporus sp & 149 & 0,362 \\
& & 115 & 0,336 \\
& & Polyporus sp & 1 & 0,012 \\
& & Polyporus squamosus & 3 & 0,038 \\
& & Coriolus hirsutus & 8 & 0,086 \\
& & Pycnoporus cinnabarinus & 1 & 0,012 \\
& & Tyromyces sambuceus & 13 & 0,124 \\
& & Fomytopsis pinicola & 5 & 0,059 \\
& & Microporus perula & 9 & 0,094 \\
& & Trametes orientalis & 1 & 0,012 \\
2 & Auriculariaceae & Piptoporus betulinus & 1 & 0,012 \\
& & Auricula polytricha & 5 & 0,059 \\
3 & Ganodermataceae & Auricularia auricula & 5 & 0,059 \\
& & Elfvingia applanata & 2 & 0,026 \\
4 & Tricholomataceae & 6 & 0,069 \\
5 & Paxillaceae & Laccaria vinaceoavellaneae & 3 & 0,038 \\
6 & Pleurotaceae & Paxillus curtisii & 13 & 1,24 \\
\hline \hline & & Jumlarotus pulmorius & $\mathbf{3 4 0}$ & $\mathbf{1 , 5 1 0}$
\end{tabular}

Diversitas sangat tergantung pada kemerataan individu antar spesies dan bukan semata-mata pada kekayaan spesiesnya sehingga yang menyebabkan naiknya nilai indeks 
diversitas adalah kemerataan antarspesies. Jika selisih semakin besar, maka kemerataan semakin berkurang, sebaliknya jika selisih jumlah individu antarspesies semakin kecil, maka kemerataan semakin tinggi. Kemerataan semakin maksimum bila semua spesies mempunyai individu yang sama sehingga terjadilah keanekaragaman spesies, karena diversitas spesies adalah gabungan kekayaan dan kemerataan.

Jenis-jenis jamur yang ditemukan di hutan cagar alam Gunung Mutis ditampilkan pada Tabel 1 dengan diagram jenis-jenis jamur yang ditampilkan pada Gambar 2. Jenis jamur yang paling mendominasi hutan cagar alam ini berasal dari famili Polyporaceae dengan ciri fisik basidiokarp lebar dan kaku serta berwarna kuning kecoklatan dan bertangkai serta hidup berkelompok pada kayu kering dan daerah lembab dengan keberadaan pepohonan yang tinggi. Salah satu jenis dari famili Polyporaceae adalah spesies Polyporus sp yang memiliki bentuk tubuh menyerupai kipas mini dan keras serta kaku pada musim kemarau. Bentuk dan ukuran setengah lingkaran dengan warna putih kecoklatan, dapat dengan mudah dijumpai di daerah yang lembab dan dapat tumbuh dengan baik pada kayu yang tingkat kelapukannya masih rendah (belum begitu hancur) atau masih dikategorikan sebagai kayu kering.

Spesies jamur Pleurotus pulmorius hidup yang berkelompok atau berklaster pada kayu yang sudah mati, ternaungi oleh pepohonan, memiliki suhu yang dingin yaitu sekitar $6^{\circ} \mathrm{C}$ hingga $22^{\circ} \mathrm{C}$. Spesies jamur ini dapat dibedakan dengan spesies lain dengan melihat morfologisnya berwarna putih, tidak bertangkai, memiliki lamela atau gills yang berwarna putih, tumbuh di daerah lembab, dan bagian bawah basidiokarpnya berwarna putih, tudung atau basidiokarpnya berbentuk setengah lingkaran mirip dengan cangkang pada tiram dengan bagian tengah agak cekung. Adapun penampakan morfologi jenis-jenis jamur yang ditemukan di hutan cagar alam Gunung Mutis ditampilkan pada Gambar 2.

Menurut Sastrawidana (2015), bahwa pigmen warna dari jamur berfungsi untuk melindungi dinding hifa atau dinding spora jamur dari pengaruh radiasi. Pigmen yang dihasilkan oleh jamur umumnya termasuk golongan anthraquinone, karotenoid, flavonoid, kuinin dan rubramin. Pembentukan pigmen oleh jamur pada umumnya dipengaruhi oleh berbagai faktor diantaranya cahaya, suhu, dan komposisi medium. Kandungan nutrien organik, logam dan mineral di dalam medium sangat berpengaruh terhadap pertumbuhan dan pembentukan pigmen oleh Monascus. Kandungan fosfat yang tinggi (>70 mM) dapat menghambat pertumbuhan. Monascus dan pembentukan pigmennya, sedangkan konsentrasi yang tinggi dari $\mathrm{MgSO}_{4}$ (16 mM) akan memacu pertumbuhan Monascus tetapi akan menghambat pertumbuhan pigmennya. Pembentukan pigmen ini dapat meningkat dengan penambahan logam-logam berat, khususnya $\mathrm{Zn}$. Ion $\mathrm{Zn}{ }^{2+}$ merupakan salah satu nutrien yang paling penting bagi kehidupan organisme karena berperan dalam aktivitas beberapa enzim, antara lain sebagai kofaktor enzim karbonat anhidrase.

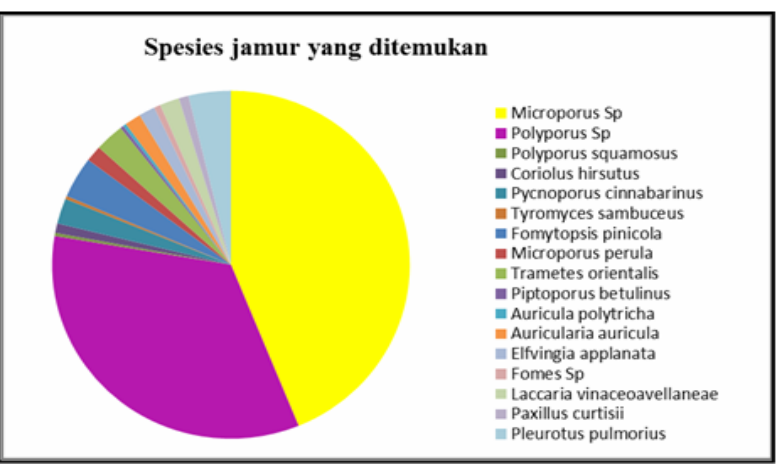

Gambar 2. Diagram jenis-jenis jamur di cagar alam Gunung Mutis. 


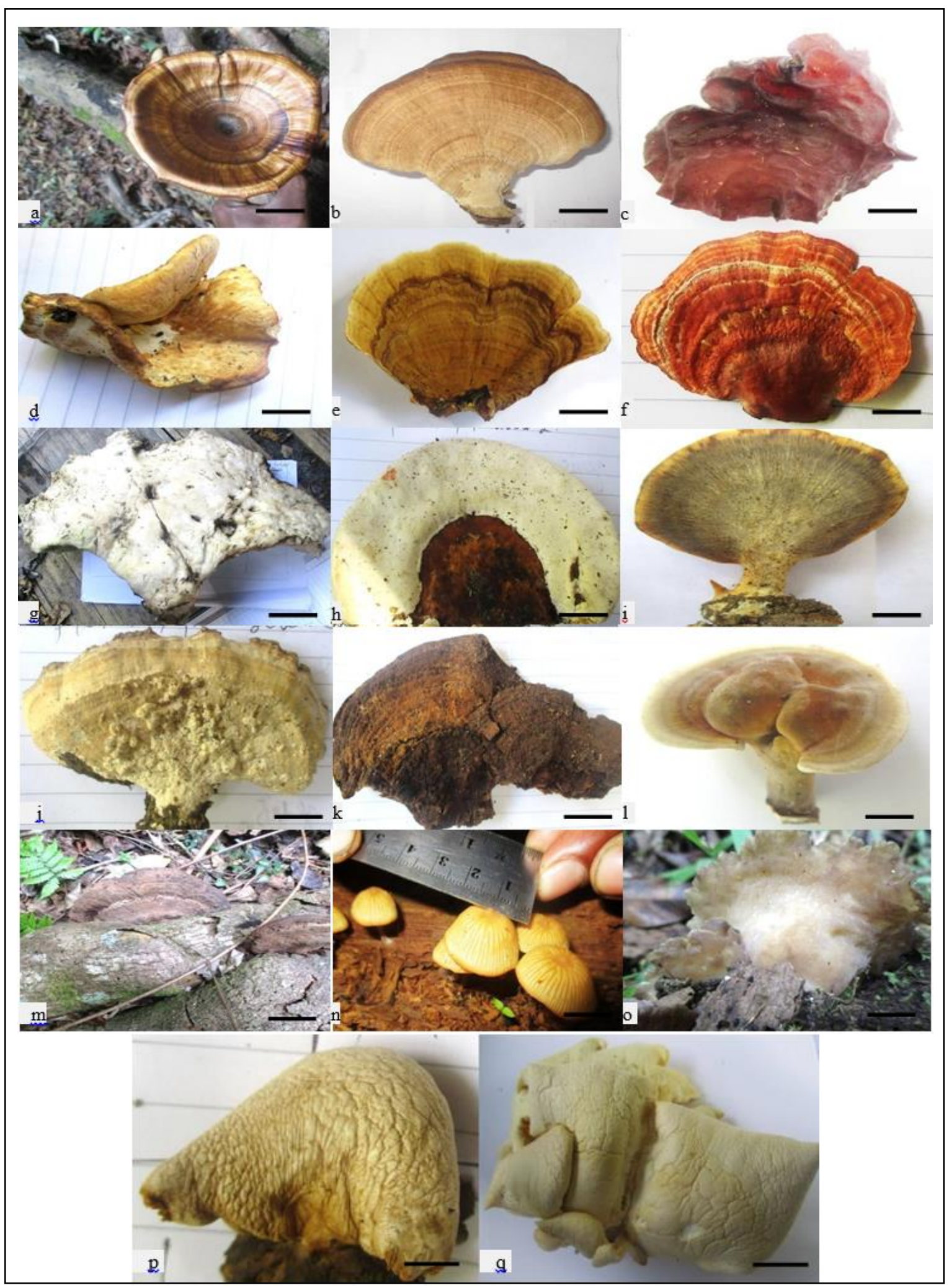

Gambar 3. Spesies jamur yang ditemukan: a) Microporus sp; b) Polyporus sp; c) Auricularia polytricha; d) Polyporus squamosus; e) Coriolus hirsutus; f) Pycnoporus cinnabarinus; g) Tyromyces sambuceus; h) Fomitopsis pinicola; i) Microporus perula ; j) Trametes orientalis; k) Fomes sp ; 1) Piptoporus betulinus; m) Elfvingia applanata; n) Laccaria vinaceoavellaneae; o) Auricularia auricular; p) Paxilus curtisii ; q) Pleurotus pulmorius. Skala bar $1 \mathrm{~cm}$. 


\section{Simpulan}

Jamur makro yang terdapat di dalam kawasan cagar alam gunung Mutis yaitu berjumlah 340 individu dari 17 spesies. Tingkat keanekaragaman jamur $\left(\mathrm{H}^{\prime}\right)$ yaitu 1,510 , yang menunjukkan tingkat keragaman yang tinggi.

\section{Ucapan Terima Kasih}

Ucapan terima kasih yang sangat dalam kepada Dr. Simon Taka Nuhamara (almarhum), dosen studi pendidikan Biologi UKAW, sebagai pembimbing dalam penelitian ini.

\section{Daftar pustaka}

Anggriawan, I. 2014. Inventarisasi Jamur Tingkat Tinggi (Basidiomycetes) Di Gunung Singgalang Sumatera Barat. Jurnal Biologi Universitas Andalas (J. Bio. UA.) 3(2)-Juni 2014 : 147$153($ ISSN : 2303-2162)
Campbell, Reece, Urry, Cain, Wasserman, Minorsky dan Jackson, 2012. Biologi Edisi Kedelapan Jilid 2. Erlannga: Jakarta.

Darwis, W. 2011. Inventarisasi Jamur Yang Dapat Dikonsumsi Dan Beracun Yang Terdapat Di Hutan Dan Sekitar Desa Tanjung Kemuning Kaur Bengkulu. Konservasi Hayati, 7 (2). pp. 1 8. ISSN 0216-9487

Imazeki, R., Otani, Y. dan Hongo, T. 1988. Fungi Of Japan. YAMA-KEI Publishers.co ltd, 1-3-33, Shiba - Daimon, Minato-ku, Tokyo - Japan.

Proborini, W. M. 2006. Eksplorasi Dan Identifikasi JenisJenis Jamur Klas Basidiomycetes Di Kawasan Bukit Jimbaran Bali. Jurnal Biologi, XVI(2): 45 $-47$.

Sastrawidana, I.D.K. 2015. Pigmen Merah Dari Jamur Yang Diisolasi Dari Tanah Tempat Pembuangan Limbah Susu. Jurnal Kimia Online, 9 (1): 7-12.

Stalker, P. 2008. Millennium Development Goals Cetakan Kedua. Laporan BAPPENAS dan UNDP.

Tampubolon, J. 2010. Inventarisasi Jamur Makroskopis Di Kawasan Ekowisata Bukit Lawang Kabupaten Langkat Sumatera Utara. Tesis: USU 